\title{
Pfcrt haplotypes and the evolutionary history of chloroquine-resistant Plasmodium falciparum
}

\author{
Gauri Awasthi', Godavarthi Bhogendra Krishna Satya ${ }^{2}$, Aparup Das ${ }^{1 /+}$ \\ 'Evolutionary Genomics and Bioinformatics Laboratory, Division of Genomics and Bioinformatics, National Institute of Malaria Research, \\ Sector 8, 110077 New Delhi, India ${ }^{2}$ School of Studies in Biotechnology, Jiwaji University, Madhya Pradesh, India
}

\begin{abstract}
Mutations in the Pfcrt gene that change the resulting amino acids and form different haplotypes are common and correlate with the prevalence of chloroquine resistant (CQR) field isolates of the malaria parasite, Plasmodium falciparum. This correlation provides opportunities to infer the global evolutionary history of CQ resistance by analysing CQR Pfcrt haplotype data. We collated data on the Pfcrt haplotypes from different global studies and performed evolutionary genetic analysis to present comprehensive and comparative information on the global distribution of five major CQR-Pfcrt haplotypes and evolutionary inter-relationships among 38 different countries. Using the haplotype diversity data, inter-continental genetic differentiation was also ascertained.
\end{abstract}

Key words: CQR-Pfcrt haplotypes - malaria - evolution

The origin and spread of chloroquine resistance (CQR) in Plasmodium falciparum have grossly hampered global malaria control programmes. The genetic basis of CQR has been previously characterised; primarily two genes, the P. falciparum CQR transporter $(P f c r t)$ gene and the $P$. falciparum multi-drug resistance ( $P f m d r l)$ gene have been directly and indirectly implicated, respectively (Fidock et al. 2000). Several studies have inconclusively indicated correlations between development of CQR and mutations in the Pfmdrl gene, but they have shown direct positive correlations between development of $\mathrm{CQR}$ and amino acid substitutions (lysine to threonine at the 76th position, commonly known as K76T) in the Pfcrt gene (Fidock et al. 2000). Thus, the Pfcrt gene has become the main genetic marker for $\mathrm{CQR}$ in $P$. falciparum (Fidock et al. 2000, Wootton et al. 2002). However, others have proposed that the K76T mutation does not act alone but in conjunction with other surrounding mutations (Mehlotra et al. 2001). Accordingly, mutations in the 72nd-76th positions of the Pfcrt gene that were found in a majority of $P$. falciparum endemic areas are now also considered as molecular markers used for detecting CQR malaria parasites in field isolates. CQR is a widespread phenomenon in almost all of the $P$. falciparum endemic regions and the prevalence of the five polymorphisms that form different haplotypes varies among the $P$. falciparum endemic regions. Although several studies report on the prevalence and distribution of different $P f c r t$ haplotypes in to the 72nd-76th position within individual regions, no comprehensive and comparative

Financial support: ICMR/New Delhi

GA is a senior research fellow of ICMR/New Delhi.

+ Corresponding author: aparup@mrcindia.org

Received 9 June 2011

Accepted 20 October 2011 studies of either the distribution by country of PfcrtCQR haplotypes in P. falciparum or global evolutionary relationships are available.

With regard to the mutations at the 72nd-76th position, the ancestral [CQ sensitive (CQS)] haplotype is known as $\mathrm{C}_{72} \mathrm{~V}_{73} \mathrm{M}_{74} \mathrm{~N}_{75} \mathrm{~K}_{76}$ which is different from the derived CQR haplotypes $\left(\mathrm{C}_{72} \mathrm{~V}_{73} \mathrm{I}_{74} \mathrm{E}_{75} \mathrm{~T}_{76}\right.$ and $\mathrm{S}_{72} \mathrm{~V}_{73} \mathrm{M}_{74}$ $\mathrm{N}_{75} \mathrm{~T}_{76}$ ). Although two major derived (resistant) haplotypes [SVMNT and CVIET, also referred to as the CQR mother haplotypes by Awasthi et al. (2011)] are distributed primarily in the CQ-resistant malaria endemic zones in high frequencies, three derived haplotypes (from a total of 15) are also found in appreciable frequencies across the globe.

We collected independently published data on the prevalence, distribution and frequencies of all 15 haplotypes for each country (Basco \& Ringwald 2001, Mehlotra et al. 2001, 2008, Cortese et al. 2002, Kublin et al. 2003, Lim et al. 2003, Mu et al. 2003, Nagesha et al. 2003, Vinayak et al. 2003, 2006, Huaman et al. 2004, Millet et al. 2004, Plummer et al. 2004, Vathsala et al. 2004, Vieira et al. 2004, Anderson \& Roper 2005, Cooper et al. 2005, Dittrich et al. 2005, Alifrangis et al. 2006, Jiang et al. 2006, Menard et al. 2006, Mishra et al. 2006, Mittra et al. 2006, Randrianarivelojosia et al. 2006, Severini et al. 2006, DaRe et al. 2007, Echeverry et al. 2007, Fatemeh et al. 2007, Keen et al. 2007, Pati et al. 2007, Yang et al. 2007, Niang et al. 2008, Pineda et al. 2008, Restrepo et al. 2008, Zakeri et al. 2008, Almeida et al. 2009, Lumb et al. 2009, Gama et al. 2010, Mixson-Hayden et al. 2010) and merged the information to obtain distribution of different haplotypes by country. It was clear that there are only five major haplotypes associated with CQR (CVIET, SVMNT, SVIET, CVMNT and CVTNT) in global parasite populations; however, there are many other possible combinations of polymorphisms in positions 72-76 that include the key mutation K76T. Among these five haplotypes, the most common haplotypes globally are CVIET and SVMNT. Surprisingly, CVMNT (the CQR haplotype that is closest to the 
ancestral CQS haplotype CVMNK) is relatively uncommon among them, suggesting that the shortest trajectory to $\mathrm{CQR}$ (a single mutation, leading from the ancestral CVMNK haplotype to the CQR haplotype CVMNT) is rarely observed in nature. This finding suggests that compensatory mutations in codons other than position 76 may be required to restore the fitness of the CQR parasites bearing the K76T mutation. Accordingly, we infer possible mutational trajectories from the ancestral CVMNK (CQS) to different CQR haplotypes. A hypothetical sketch of the possible step-wise mutation events from the ancestral CVMNK to different CQR haplotypes is provided in Fig. 1.

The results of the frequency distribution of the five CQR haplotypes (CVIET, SVMNT, SVIET, CVMNT and CVTNT) reveal that almost all of the African countries are populated predominantly by the CVIET haplotype in almost absolute frequencies (except for Tanzania and Congo) (Fig. 2). This discrepancy might be due to the recent report of the SVMNT haplotype in Tanzania (Alifrangis et al. 2006) and Angola (Gama et al. 2010). Similarly, the South American P. falciparum isolates seem to be thickly populated with the SVMNT haplotypes and the southeast Asian populations have a mixture of all of the five Pfcrt haplotypes (CVIET, SVMNT, SVIET, CVMNT and CVTNT) (Fig. 2). There seems to be a very clear haplotype structure across the malaria endemic regions of the world (Fig. 2). We also calculated the frequencies of these five haplotypes in each of the 38 countries separately and estimated Nei's genetic distance (Nei 1972) between each possible pair of populations $(1,406$ possible pairs in total) using the GeneDist program integrated within the PHYLIP-Phylogeny Inference Package v. 3.68 [distributed by J Felsenstein (2004), Department of Genome Sciences, University of Washington, Seattle, USA]. We used the genetic distance matrix to construct

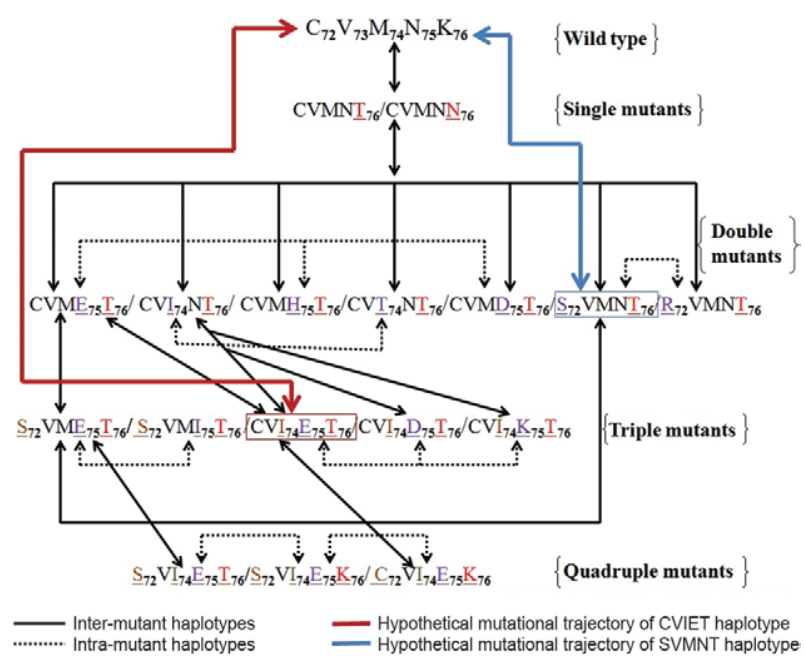

Fig. 1: hypothetical sketch displaying mutational trajectory leading to different chloroquine (CQ) resistance-Plasmodium falciparum transporter haplotype from the ancestral CVMNK (CQ sensitive) haplotype. a neighbour-joining $(\mathrm{NJ})$ population phylogenetic tree employing the Molecular Evolutionary Genetics Analysis computer program v. 4.0 (Tamura et al. 2007). The $\mathrm{NJ}$ tree produced two major clades, one comprising the CVIET and SVIET haplotypes and the other comprising the SVMNT, CVMNT and CVTNT haplotypes (Fig. 3). The smaller (SVMNT, CVMNT and CVTNT) clade consisted of 13 countries [3 southeast Asian countries, Papua New Guinea (PNG), India, Iran and all of the seven South American countries]; the larger (CVIET and SVIET) clade bears 25 countries (23 African countries and two southeast Asian countries) (Fig. 3). We generally found a perfect correlation between the distributions of the five haplotypes among the countries (Fig. 2) and the populations appearing on the phylogenetic trees (Fig. 3 ). Interestingly, the aggregation of countries into a particular clade seems unrelated to both their geographic locations and their continental boundaries. For example, India is placed in a monophyletic position with Ecuador (Fig. 3), which is not consistent with the distribution of the different $P f c r t$ haplotypes (Fig. 2).

Utilising the frequency distribution of the five Pfcrt haplotypes (CVIET, SVMNT, SVIET, CVMNT and CVTNT) in 38 countries, we documented the intercontinental genetic differentiation and migration patterns of CQR P. falciparum. For this analysis, we merged the haplotype frequency information from all of the countries into three continents (Africa, South America and Asia) and estimated the population pair-wise $F_{s t}$ (Wright 1969) values between each pair of continents using the computer program GenePop v. 4.0 (Rousset 2008). We took the liberty of merging the data from southeast Asia, PNG, India and Iran into the Asian continent. The amount of genetic differentiation was higher between Africa and Asia $\left(F_{s t}=0.3243\right)$ than between South America and Asia $\left(F_{s t}^{s t}=0.1286\right)$. However, a very high $F_{s t}$ value $\left(F_{s t}=\right.$ 0.6843 ) was found between Africa and South America. Furthermore, to determine whether the data fit the isolation-by-distance (IBD) model of population structure

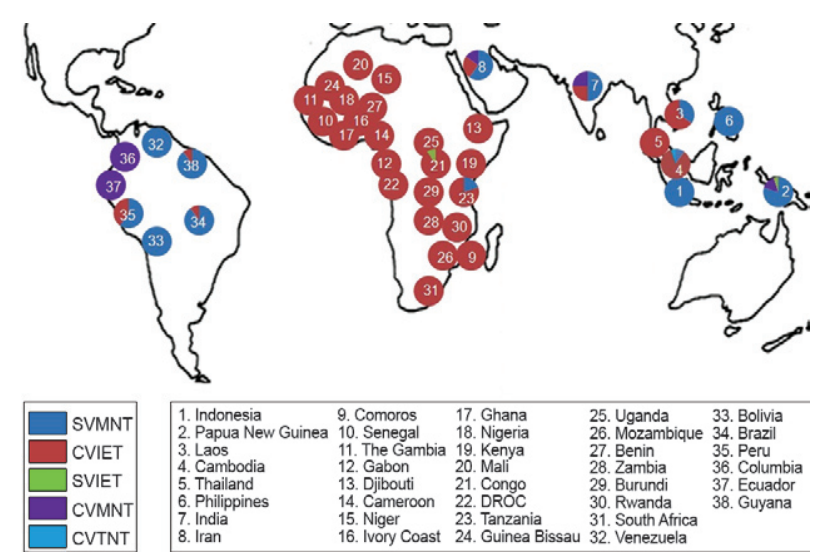

Fig. 2: frequency distribution of the five most common chloroquine resistance-Plasmodium falciparum transporter haplotypes (CVIET, SVMNT, SVIET, CVMNT and CVTNT) in the 38 malaria endemic countries. 
(Wright 1943), we calculated the geographic distance between the capital cities in each pair of countries and calculated the genetic distance utilising the online computer program IBDSW v. 3.16 (ibdws.sdsu.edu/ ibdws/). This analysis yielded a statistically significant positive value $(\mathrm{r}$ $=0.404 ; \mathrm{p}<0.0010$ ). These data provide evidence in support of the fact that similarities between the Pfcrt haplotypes are highly dependent on the geographic distance between the countries. Furthermore, we employed the pair-wise $F_{s t}$ values between continents to estimate the mean number of effective migrants in each generation $\left(N_{m}\right)$ (Wright 1978) and, surprisingly, detected a greater number of effective migrants of CQR parasites between South America and Asia $\left(N_{m}=1.69\right)$ than between Asia and Africa $\left(N_{m}=0.52\right)$ (Fig. 3). However, a comparatively lower level of Pfcrt haplotype migration was detected between Africa and South America $\left(N_{m}=0.11\right)$. Considering that the initial evolution of the SVMNT haplotype occurred in South America (Sa et al. 2009) followed by another independent origin in PNG (Mehlotra et al. 2001, Awasthi et al. 2011), the results could be interpreted to represent the rapid movement of the SVMNT haplotype between South America and PNG. Further evidence for this inference is the fact that the Indian SVMNT type was found to be of the PNG type by DNA sequencing of the 2nd exon in Indian isolates (Awasthi et al. 2011). Similarly, the CVIET haplotype is believed to have originated in southeast Asia and accordingly was found to have migrated from southeast Asia to Africa via India (Awasthi et al. 2011) (Fig. 4). However, a very meagre number of $P f_{c} r t$ haplotypes could have been exchanged between South America and Africa (Fig. 4). This result

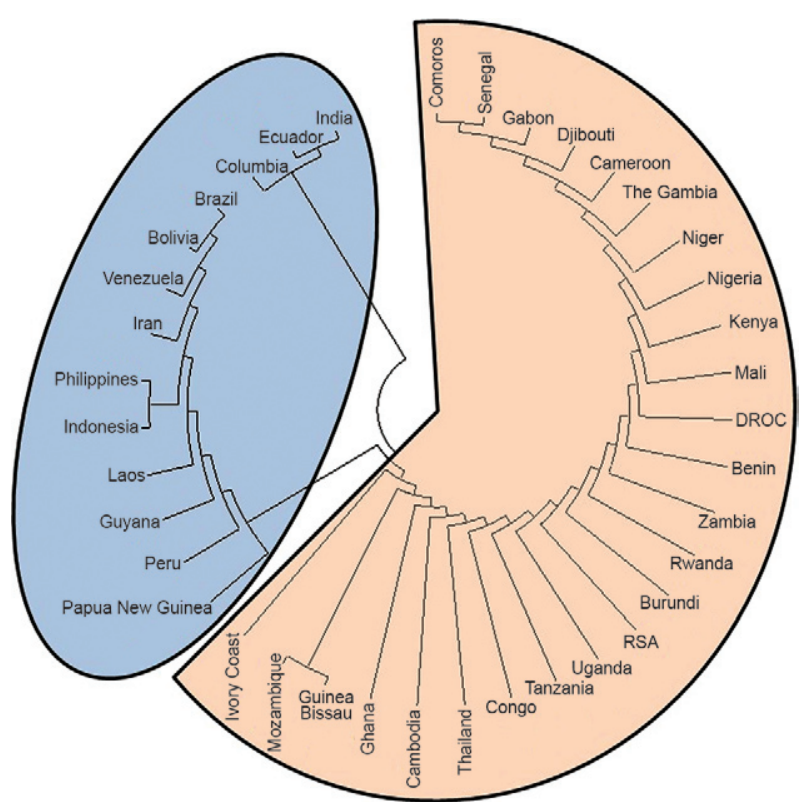

Fig. 3: neighbour-joining tree to understand evolutionary relationship among 38 populations (countries) where chloroquine resistance is prevalent. The smaller clade depicts SVMNT, CVMNT and CVTNT dominated countries whereas the bigger clade depicts CVIET and SVIET dominated countries. agrees with the population phylogenetic analysis (Fig. 3 ), in which the smaller clade (SVMNT) was found to represent countries from Asia, PNG and South Ameri$\mathrm{ca}$, whereas the larger clade (CVIET) represents a large proportion of African countries and only two southeast Asian countries (Fig. 3).

How important and relevant is this information (Pfcrt haplotype global evolutionary history) in terms of $P$. falciparum CQR management and future malaria control measures? The population and evolutionary genetic analyses of different Pfcrt haplotypes provide baseline information to correlate the intercontinental usage of antimalarial agents and successful establishment of CQR P. falciparum in different places around the world. For example, in South America, use of amodiaquine and $\mathrm{CQ}$, which have not been used for the last several years, have resulted in the complete fixation of the SVMNT haplotype (Sa et al. 2009). There exist only two single reports of the CVMNK CQS allele in South America (Brazil and Venezuela) (Contreras et al. 2002, Gama et al. 2011). Moreover, it is reported that even in the absence of drug pressure, the SVMNT haplotype provides equal fitness to the parasite (as was in presence of drug pressure) in comparison to the CVIET haplotype (Sa et al. 2009). Furthermore, in the absence of CQ, the CVIET haplotype-bearing P. falciparum are known to revert back to the CQS type upon treatment with the CQR-reversing agent verapamil, whereas the SVMNT-bearing P. falciparum do not (Sa et al. 2009). This finding is supported by the fact that non-usage of CQ in some countries, such as Kenya (Mwai et al. 2009), Malawi (Kublin et al. 2003) and China (Wang et al. 2005), have resulted in reversion to the ancestral state of CQS from the CQR CVIET haplotype, whereas this reversion was not observed for the SVMNT haplotype (Sa et al. 2009).

The two CQR mother haplotypes (CVIET and SVMNT) have different foci of origin, e.g., CVIET in southeast Asia and SVMNT in South America and PNG (Mehlotra et al. 2001). However, approximately $60 \%$ of the total Pfcrt-CQR haplotypes in southeast Asia and India had the SVMNT haplotype, imported from PNG (Figs

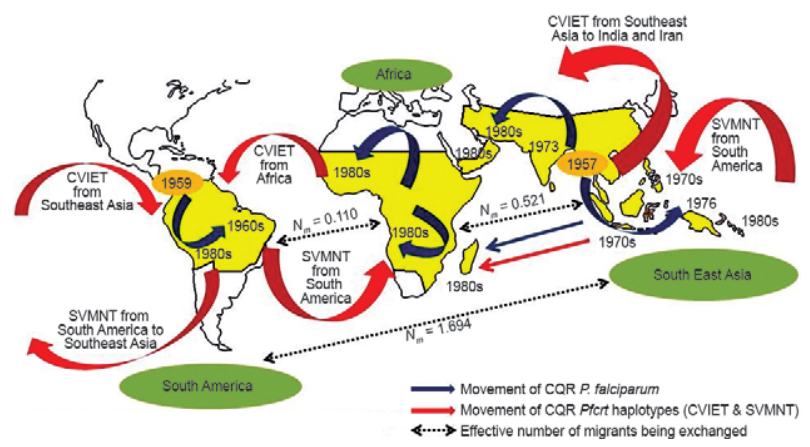

Fig. 4: estimated genetic differentiation and inferred hypothetical migration patterns of chloroquine resistance-Plasmodium falciparum transporter haplotypes among four malaria endemic continents (southeast Asia, Papua New Guinea, Africa and South America). $N_{m}$ : mean number of effective migrants in each generation. 
$2,4)$. This observation fits well with the high rate of ongoing migration of the SVMNT haplotypes from PNG to southeast Asia (Fig. 4) and a moderate level of migration of the CVIET haplotypes from southeast Asia to Africa via India (Awasthi et al. 2011). Since it is proposed that $N_{m}>1$ is enough to overcome the genetic differentiation between two populations (Wright 1978), the current migration rate is frightening for global CQR management. This situation is especially daunting because a very high migration rate has been documented for the frequent haplotype, SVMNT, which does not revert back to CQS even when CQ is withdrawn from the malaria control program (Sa et al. 2009, Awasthi et al. 2011).

However, to visualise the relevance of such information in a public health perspective, an absolute correlation between the Pfcrt gene and CQR P. falciparum must first be ascertained because several studies have indicated that the Pfcrt-K76T mutation might not be the sole determinant of CQR in P. falciparum (Mehlotra et al. 2001, 2008, Das \& Dash 2007). Furthermore, the global pattern of natural selection and evolution of the Pfcrt gene seems different from that of the Pfcrt gene in the Indian P. falciparum (Wootton et al. 2002, Das \& Dash 2007). Considering that the 7th chromosomal region surrounding the Pfcrt is tightly linked (Fowler et al. 2006, Volkmann et al. 2007, Gupta et al. 2010, Mu et al. 2010), more genetic studies in this region are needed to clearly ascertain the specific role played by the $P f c r t$ gene in conferring CQR on P. falciparum. Furthermore, genetic diversity patterns of the microsatellite loci flanking the mutations between positions 72 and 76 could also provide valuable insight into the evolutionary pattern of the Pfcrt gene in general (Ariey et al. 2006, Mixson-Hayden et al. 2010). However, the absence of such data from all of the studies discussed here debars us from establishing any relationships among the evolutionary histories of the CQR-Pfcrt haplotypes.

In conclusion, the overall results of the present evolutionary genetic study reflecting the distribution, frequencies and migration patterns of different CQR-Pfcrt haplotypes provides valuable information on the evolutionary history of the haplotypes (and possibly of the CQR P. falciparum) that could be used for CQR management (Escalante et al. 2009). Considering the high fitness properties of the SVMNT haplotype in the absence of CQ pressure (relative to the corresponding CVIET haplotype) and the high rate of intercontinental migration and successful establishment of this haplotype, the current CQR situation seems daunting for CQR malaria management programs in southeast Asia and in India (Vinayak et al. 2003, 2006, Restrepo et al. 2008, Awasthi et al. 2011). While the information presented here establishes the influence of positive natural selection of the SVMNT haplotype, other determinants (both genetic and environmental) might also play a role in the successful establishment of CQR P. falciparum.

\section{ACKNOWLEDGEMENTS}

To ICMR, for providing intramural funding (to AD), to Hemlata Srivastava and Huguette Gaelle Ngassa Mbenda, for help at initial stages of the work, and two anonymous reviewers, for constructive criticisms on an earlier version of the paper.

\section{REFERENCES}

Alifrangis M, Dalgaard MB, Lusingu JP, Vestergaard LS, Staalsoe T, Jensen ATR, Enevold A, Rønn AM, Khalil IF, Warhurst DC, Lemnge MM, Theander TG, Bygbjerg IC 2006. Occurrence of the southeast Asian/South American SVMNT haplotype of the chloroquine-resistance transporter gene in Plasmodium falciparum in Tanzania. J Infect Dis 193: 1738-1741.

Almeida AD, Arez AP, Cravo PVL, Rosário VED 2009. Analysis of genetic mutations associated with anti-malarial drug resistance in Plasmodium falciparum from the Democratic Republic of East Timor. Malar J 8: 59.

Anderson TJC, Roper C 2005. The origins and spread of antimalarial drug resistance: lessons for policy makers. Acta Trop 94: 269-280.

Ariey F, Fandeur T, Durand R, Randrianarivelojosia M, Jambou R, Legrand E, Ekala MT, Bouchier C, Cojean S, Duchemin JB, Robert V, Bras JL, Mercereau-Puijalon O 2006. Invasion of Africa by a single pfcrt allele of South East Asian type. Malar J 5: 34.

Awasthi G, Prasad GBKS, Das A 2011. Population genetic analyses of Plasmodium falciparum chloroquine receptor transporter gene haplotypes reveal the evolutionary history of chloroquine-resistant malaria in India. Int J Parasitol 41: 705-709.

Basco LK, Ringwald P 2001. Analysis of the key Pfcrt point mutation and in vitro and in vivo response to chloroquine in Yaoundé Cameroon. J Infect Dis 183: 1828-1831.

Contreras CE, Cortese JF, Carballo A, Plowe CV 2002. Genetics of drug-resistant Plasmodium falciparum malaria in the Venezuelan state of Bolivar. Am J Trop Med Hyg 67: 400-405.

Cooper RA, Hartwig CL, Ferdig MT 2005. Pfcrt is more than the Plasmodium falciparum chloroquine resistance gene: a functional and evolutionary perspective. Acta Trop 94: 170-180.

Cortese JF, Caraballo A, Contreras CE, Plowe CV 2002. Origin and dissemination of Plasmodium falciparum drug-resistance mutations in South America. J Infect Dis 186: 999-1006.

DaRe JT, Mehlotra RK, Michon P, Mueller I, Reeder J, Sharma YD, Stoneking M, Zimmerman PA 2007. Microsatellite polymorphism within Pfcrt provides evidence of continuing evolution of chloroquine-resistant alleles in Papua New Guinea. Malar J 6: 34.

Das A, Dash AP 2007. Evolutionary paradigm of chloroquine-resistant malaria in India. Trends Parasitol 23: 132-135.

Dittrich S, Alifrangis M, Stohrer JM, Thongpaseuth V, Vanisaveth V, Phetsouvanh R, Phompida S, Khalil IF, Jelinek T 2005. Falciparum malaria in the north of Laos: the occurrence and implications of the Plasmodium falciparum chloroquine resistance transporter ( $P f c r t)$ gene haplotype SVMNT. Trop Med Int Health 10: 1267-1270.

Echeverry DF, Holmgren G, Murillo C, Higuita JC, Bjorkman A, Gil JP, Osorio L 2007. Polymorphims in the Pfcrt and Pfmdrl genes of Plasmodium falciparum and in vitro susceptibility to amodiaquine and desethylamodiaquine. Am J Trop Med Hyg 77: 1034-1038.

Escalante AA, Smith DL, Kim Y 2009. The dynamics of mutations associated with anti-malarial drug resistance in Plasmodium falciparum. Evol Parasitol 25: 557-563.

Fatemeh J, Abdolhossein D, Siamak MS, Fatemeh G, Faramarz S, Ramin N 2007. Application of real-time PCR for detection of Pfcrt single nucleotide polymorphisms in Plasmodium falciparum in southeast Iran. J Med Sciences 7: 1082-1087.

Fidock DA, Nomura T, Talley AK, Cooper RA, Dzekunov SM, Ferdig MT, Ursos Lyann MB, Sidhu ABS, Naude B, Deitsch KW, Su XZ, Wootton JC, Roepe PD 2000. Mutations in the P. falciparum digestive vacuole transmembrane protein $P f c r t$ and evidence for their role in chloroquine resistance. Mol Cell 6: 861-871. 
Fowler EV, Chavchich M, Chen N, Peters JM, Kyle DE, Gatton ML, Cheng Q 2006. Physical linkage to drug resistance genes results in conservation of var genes among west pacific Plasmodium falciparum isolates. J Infect Dis 194: 939-948.

Gama BE, Lacerda MVG, Daniel-Ribeiro CT, Ferreira-da-Cruz M de F 2011. Chemoresistance of Plasmodium falciparum and Plasmodium vivax parasites in Brazil: consequences on disease morbidity and control. Mem Inst Oswaldo Cruz 106 (Suppl. I): 159-166.

Gama BE, Pereira-Carvalho GAL, Lutucuta Kosi FJI, Almeida de Oliveira NK, Fortes F, Rosenthal PJ, Daniel-Ribeiro CT, Ferreira-daCruz M de F 2010. Plasmodium falciparum isolates from Angola show the SVMNT haplotype in the Pfcrt gene. Malaria J 9: 174.

Gupta B, Awasthi G, Das A 2010. Malaria parasite genome scan: insights into antimalarial resistance. Parasitol Res 107: 495-499.

Huaman MC, Yoshinaga K, Suryanatha A, Suarsana N, Kanbara H 2004. Polymorphisms in the chloroquine resistance transporter gene in Plasmodium falciparum isolates from Lombok, Indonesia. Am J Trop Med Hyg 71: 40-42.

Jiang H, Joy DA, Furuya T, Su XZ 2006. Current understanding of the molecular basis of chloroquine-resistance in Plasmodium falciparum. J Postgrad Med 52: 271-276.

Keen J, Farcas GA, Zhong K, Yohanna S, Dunne MW, Kain KC 2007. Real-time PCR assay for rapid detection and analysis of Pfcrt haplotypes of chloroquine-resistant Plasmodium falciparum isolates from India. J Clin Microbiol 45: 2889-2893.

Kublin JG, Cortese JF, Njunju EM, Mukadam RA, Wirima JJ, Kazembe PN, Djimde AA, Kouriba B, Taylor TE, Plowe CV 2003. Reemergence of chloroquine-sensitive Plasmodium falciparum malaria after cessation of chloroquine use in Malawi. J Infect Dis 187: 1870-1875.

Lim P, Chy S, Ariey F, Incardona S, Chim P, Sem R, Denis MB, Hewitt S, Hoyer S, Socheat D, Odile MP, Thierry F 2003. Pfcrt polymorphism and chloroquine resistance in Plasmodium falciparum strains isolated in Cambodia. Antimicrob Agents Chemother 47: 87-94.

Lumb V, Das MK, Mittra P, Ahmed A, Kumar M, Kaur P, Dash AP, Singh SS, Sharma YD 2009. Emergence of an unusual sulfadoxine-pyrimethamine resistance pattern and a novel K540N mutation in dihydropteroate synthetase in Plasmodium falciparum isolates obtained from Car Nicobar Island, India, after the 2004 tsunami. J Infect Dis 199: 1064-1073.

Mehlotra RK, Fujioka H, Roepe PD, Janneh O, Ursos LMB, JacobsLorena V, McNamara DT, Bockarie MJ, Kazura JW, Kyle DE, Fidock DA, Zimmerman PA 2001. Evolution of a unique Plasmodium falciparum chloroquine-resistance phenotype in association with Pfcrt polymorphism in Papua New Guinea and South America. Proc Natl Acad Sci 98: 12689-12694.

Mehlotra RK, Mattera G, Bockarie MJ, Maguire JD, Baird JK, Sharma YD, Alifrangis M, Philip GD, Rosenthal J, Fryauff DJ, Kazura JW, Stoneking M, Zimmerman PA 2008. Discordant patterns of genetic variation at two chloroquine resistance loci in worldwide populations of the malaria parasite Plasmodium falciparum. Antimicrob Agents Chemother 52: 2212-2222.

Menard D, Yapou F, Manirakiza A, Djalle D, Matsika-Claquin MD, Talarmin A 2006. Polymorphisms in Pfcrt, Pfmdrl, dhfr genes and in vitro responses to antimalarials in Plasmodium falciparum isolates from Bangui, Central African Republic. Am J Trop Med Hyg 75: 381-387.

Millet J, Alibert S, Madamet MT, Rogier C, Rouvier CS, Bigot P, Mosnier J, Baret E, Barbe J, Parzy D, Pradines B 2004. Polymorphism in Plasmodium falciparum drug transporter proteins and reversal of in vitro chloroquine resistance by a 9,10 -dihy- droethanoanthracene derivative. Antimicrob Agents Chemother 48: 4869-4872.

Mishra S, Raj DK, Hazra RK, Dash AP, Supakar PC 2006. An efficient PCR-SSCP-based method for detection of a chloroquine resistance marker in the Pfcrt gene of Plasmodium falciparum. Trans R Soc Trop Med Hyg 100: 243-247.

Mittra P, Vinayak S, Chandawat H, Das MK, Singh N, Biswas S, Dev V, Kumar A, Ansari MA, Sharma YD 2006. Progressive increase in point mutations associated with chloroquine resistance in Plasmodium falciparum isolates from India. J Infect Dis 193: 1304-1312.

Mixson-Hayden T, Jain V, Mc Collum AM, Poe A, Nagpal AC, Dash AP, Stiles JK, Udhayakumar V, Singh N 2010. Evidence of selective sweeps in genes conferring resistance to chloroquine and pyrimethamine in Plasmodium falciparum isolates in India. Antimicrob Agents Chemother 54: 997-1006.

Mu J, Ferdig MT, Feng X, Joy DA, Duan J, Furuya T, Subramanian G, Aravind L, Cooper RA, Wootton JC, Xiong M, Su XZ 2003. Multiple transporters associated with malaria parasite responses to chloroquine and quinine. Mol Microbiol 49: 977-989.

Mu J, Myers RA, Jiang H, Liu S, Ricklefs S, Waisberg M, Chotivanich K, Wilairatana P, Krudsood S, White NJ, Udomsangpetch R, Cui L, Ho M, Ou F, Li H, Song J, Li GO, Wang X, Seila S, Sokunthea S, Socheat D, Sturdevant DE, Porcella SF, Fairhurst RM, Wellems TE, Awadalla P, Su XZ 2010. Plasmodium falciparum genome-wide scans for positive selection, recombination hot spots and resistance to antimalarial drugs. Nat Genet 42: 268-271.

Mwai L, Ochong E, Abdirahman A, Kiara SM, Ward S, Kokwaro G, Sasi P, Marsh K, Borrmann S, Mackinnon M, Nzila A 2009. Chloroquine resistance before and after its withdrawal in Kenya. Malaria J 8:106.

Nagesha HS, Casey GC, Rieckmann KH, Fryauff DJ, Laksana BS, Reeder JS, Jason DM, Baird JK 2003. New haplotypes of the Plasmodium falciparum chloroquine resistance transporter (Pfcrt) gene among chloroquine-resistant parasite isolates. Am J Trop Med Hyg 68: 398-402.

Nei M 1972. Genetic distance between populations. American Naturalist 106: 283-292.

Niang M, Marrama L, Ekala MT, Alioune G, Tall A, Ndiaye JL, Sarr D, Dangou JM, Lehesran JY, Bouchier C, Mercereau-Puijalon O, Jambou R 2008. Accumulation of CVIET Pfcrt allele of Plasmodium falciparum in placenta of pregnant women living in an urban area of Dakar, Senegal. J Antimicrob Chemother 62: 921-928.

Pati SS, Mishra S, Mohanty S, Mohapatra DN, Sahu PK, Priyadarshi N, Kumar S, Sharma SK, Tyagi PK, Chitnis CE, Dasa BS 2007. $P f c r t$ haplotypes and in-vivo chloroquine response in Sundergarh district, Orissa, India. Trans R Soc Trop Med Hyg 101: 650-654.

Pineda ER, Arango E, Maestre A, Rio VEDR, Cravo P 2008. Studies on antimalarial drug susceptibility in Colombia in relation to Pfmdrl and Pfcrt. Parasitol 135: 547-553.

Plummer WB, Pereira LMP, Carrington CVF 2004. Pfcrt and pfmdr1 alleles associated with chloroquine resistance in Plasmodium falciparum from Guyana, South America. Mem Inst Oswaldo Cruz 99: 389-392.

Randrianarivelojosia M, Fidock DA, Belmonte O, Valderramos SG, Mercereau-Puijalon O, Ariey F 2006. First evidence of pfcrt mutant Plasmodium falciparum in Madagascar. Trans $R$ Soc Trop Med Hyg 100: 826-830.

Restrepo E, Fonseca JC, Maestre A 2008. Plasmodium falciparum: high frequency of Pfcrt point mutations and emergence of new mutant haplotypes in Colombia. Biomedica 28: 523-530.

Rousset F 2008. Genepop 007: a complete reimplementation of the Genepop software for Windows and Linux. Mol Ecol Res 8: 103-106. 
Sa JM, Twu O, Hayton K, Reyes S, Fay MP, Ringwald P, Wellems TE 2009. Geographic patterns of Plasmodium falciparum drug resistance distinguished by differential responses to amodiaquine and chloroquine. Proc Natl Acad Sci 106: 18883-18889.

Severini C, Menegon M, Sannella AR, Paglia MG, Narciso P, Matteelli A, Gulletta M, Caramello P, Canta F, Xayavong MV, Moura INS, Pieniazek NJ, Taramelli D, Majori G 2006. Prevalence of Pfcrt point mutations and level of chloroquine resistance in Plasmodium falciparum isolates from Africa. Infect Genet Evol 6: 262-268.

Tamura K, Dudley J, Nei M, Kumar S 2007. MEGA4: Molecular Evolutionary Genetics Analysis (MEGA) software version 4.0. Mol Biol Evol 24: 1596-1599.

Vathsala PG, Pramanik A, Dhanasekaran S, Devi CU, Pillai CR, Subbarao SK, Ghosh SK, Tiwari SN, Sathyanarayan TS, Deshpande PR, Mishra GC, Ranjit MR, Dash AP, Rangarajan PN, Padmanaban G 2004. Widespread occurrence of the Plasmodium falciparum chloroquine resistance transporter $(P f c r t)$ gene haplotype SVMNT in P. falciparum malaria in India. Am J Trop Med Hyg 70: 256-259.

Vieira PP, Ferreira MU, Alecrim MDAC, Alecrim WD, Silva LHPD, Sihuincha MM, Joy DA, Mu J, Su XZ, Zalis MG 2004. Pfcrt polymorphism and the spread of chloroquine resistance in Plasmodium falciparum populations across the Amazon Basin. J Infect Dis 190: 417-424.

Vinayak S, Biswas S, Dev V, Kumar A, Ansari MA, Sharma YD 2003. Prevalence of the K76T mutation in the Pfcrt gene of Plasmodium falciparum among chloroquine responders in India. Acta Trop 87: 287-293.

Vinayak S, Mittra P, Sharma YD 2006. Wide variation in microsatellite sequences within each Pfcrt mutant haplotype. Mol Biochem Parasitol 147: 101-108.
Volkmann SK, Sabeti PC, Caprio DD, Neafsey DE, Schaffner SF, Milner DA, Daily JP, Sarr O, Ndiaye D, Ndir O, Mboup S, Duraisingh MT, Lukens A, Derr A, Stange-Thomann N, Waggoner S, Onofrio R, Ziaugra L, Mauceli E, Gnerre S, Jaffe DB, Zainoun J, Wiegand RC, Birren BW, Hartl DL, Galagan JE, Lander ES, Wirth DF 2007. A genome-wide map of diversity in Plasmodium falciparum. Nat Genet 39: 113-119.

Wang X, Mu J, Li G, Chen P, Guo X, Fu L, Lin C, Su XZ, Wellems TE 2005. Decreased prevalence of the Plasmodium falciparum chloroquine resistance transporter $76 \mathrm{~T}$ marker associated with cessation of chloroquine use against $P$. falciparum malaria in Hainan, people's Republic of China. Am J Trop Med Hyg 72: 410-414.

Wootton JC, Feng X, Ferdig MT, Cooper RA, Mu J, Baruch DI, Magill AJ, Su XZ 2002. Genetic diversity and chloroquine selective sweeps in Plasmodium falciparum. Nature 418: 320-323.

Wright S 1943. Isolation by distance. Genetics 28: 114-138.

Wright S 1969. Evolution and the genetics of populations: theory of gene frequencies, vol. 2, University of Chicago Press, Chicago, 295 pp.

Wright S 1978. Evolution and the genetics of populations: variability within and among natural populations, vol. 4, University of Chicago Press, Chicago, 590 pp.

Yang Z, Zhang Z, Sun X, Wan W, Cui L, Zhang X, Zhong D, Yan G, Cui L 2007. Molecular analysis of chloroquine resistance in Plasmodium falciparum in Yunnan province, China. Trop Med Int Health 12: 1051-1060.

Zakeri S, Afsharpad M, Kazemzadeh T, Mehdizadeh K, Shabani A, Djadid ND 2008. Association of Pfcrt but not $p f m d r 1$ alleles with chloroquine resistance in Iranian isolates of Plasmodium falciparum. Am J Trop Med Hyg 78: 633-640. 